\title{
INTERSETORIALIDADE E REDES: A TRAJETÓRIA DE LUCIANO ANTONIO PRATES JUNQUEIRA NA GESTÃO SOCIAL
}

\author{
INTERSECTIONALITY AND NETWORKS: LUCIANO ANTONIO PRATES JUNQUEIRA'S JOURNEY ON SOCIAL MANAGEMENT \\ INTERSECTORIALIDAD Y REDES: LA TRAYECTORIA DE LUCIANO ANTONIO PRATES JUNQUEIRA EN LA GESTIÓN SOCIAL
}

\section{RESUMO}

Por ocasião dos 80 anos do intelectual Luciano Antonio Prates Junqueira, professor e pesquisador na Pontifícia Universidade Católica de São Paulo (PUC-SP), este artigo tem por objetivo analisar sua trajetória como intelectual e a construção de um novo campo de estudos, que é gestão social. Como metodologia, para narrar sua trajetória, foram feitas entrevistas com o próprio pesquisado, além de seis pesquisadores reconhecidos do campo de gestão social e integrantes da Rede de Pesquisadores de Gestão Social. Na sustentação deste estudo, realizou-se, ainda, uma análise das citações dos artigos de Luciano Junqueira referenciados pelo Spell. Entre as contribuições do presente trabalho, a principal foi compreender o papel do intelectual como agente social, quando a sua presença e participação garantem legitimidade e fortalecem o campo do conhecimento. Além disso, observou-se que as suas características pessoais e as suas práticas de trabalho são aderentes e compartilham dos seus objetos de estudo, o que demonstra que Luciano atua de modo intersetorial, promovendo redes de compartilhamento do saber, marcadas pela confiança e afetividade.

PALAVRAS-CHAVE: Intersetorialidade, redes, intelectual, gestão social, Luciano Antonio Prates Junqueira.

\section{Maria Amelia Jundurian Corá1 \\ maria.cora@arapiraca.ufal.br \\ ORCID: 0000-0002-1366-3626}

Rodrigo Guimarães Motta²

rodrigogmotta@gmail.com

ORCID: 0000-0002-5331-0294

${ }^{1}$ Universidade Federal de Alagoas, Campus Arapiraca, Arapiraca, AL - Brasil

${ }^{2}$ Pontifícia Universidade Católica de São Paulo, PUC/SP, Brasil.

\section{Artigo convidado}

DOI: http://dx.doi.org/10.12660/cgpc.v24n79.79946 


\section{ABSTRACT}

Coinciding with the eightieth birthday of the intellectual Luciano Antonio Prates Junqueira, professor and researcher at the Pontifical Catholic University of São Paulo, this article intends to analyze both his career as an intellectual, and the construction of social management as a new area of study. Methodologically, interviews were conducted with this researcher as to narrate his trajectory, and with six other acclaimed researchers working in the field of social management, as well as member of the Social Management Researchers Network (Rede de Pesquisadores de Gestão Social). To support this study, an analysis of citations of Luciano Junqueira's articles referenced by SPELL was also performed. Among the contributions of the present work, the comprehension of the role of an intellectual as a social agent stands out, since his or her presence and participation guarantee, legitimate and strengthen this field of knowledge. Additionally, it was observed that their personal characteristics and work practices are adherent and share their objects of study, thus demonstrating that Mr. Junqueira acts in an intersectional was, promoting networks to share knowledge that are characterized by trust and affection.

KEYWORDS: Intersectionality, networks, intellectual, social management, Luciano Antonio Prates Junqueira.

\section{RESUMEN}

Con ocasión de los ochenta años del intelectual Luciano Antonio Prates Junqueira, profesor e investigador de la Pontificia Universidad Católica de San Pablo (PUC-SP/Brasil), el presente artículo tiene por objeto analizar su trayectoria como intelectual y la construcción de un nuevo campo de estúdios que es la Gestión Social. Como metodología, para narrar su trayectoria, se realizaron entrevistas al propio investigado, además de seis reconocidos investigadores del campo de la gestión social e integrantes de la Red de Investigadores de Gestión Social. Como sostén de este estudio se ha realizado también un análisis de citas de los artículos de Luciano Junqueira referidos en SPELL. Entre las contribuciones del presente trabajo, la principal ha sido comprender el papel del intelectual como agente social cuando su presencia y participación son garantia de legitimidad, fortaleciendo el campo del conocimiento. Más allá de eso, se ha observado que sus características personales y sus prácticas de trabajo son adherentes y comparten sus objetos de estudio, lo que demuestra que el profesor Junqueira actúa de forma intersectorial, promoviendo redes de intercambio de saber marcadas por confianza y afectividad.

PALABRAS CLAVE: Intersectorialidad, redes, intelectual, gestión social, Luciano Antonio Prates Junqueira.

\section{INTRODUÇÃO}

O que é rede? Rede é ligação, é relação, é a capacidade de conectar. Até o objeto que Luciano trabalha tem a ver com ele como pessoa. O objeto dele fala muito bem dele, que é a relação, o elo, o afeto. (Carrion, 2018) ${ }^{1}$

Este artigo é motivado pela celebração de 80 anos do pesquisador e docente Luciano Antonio Prates Junqueira, que se consolidou como intelectual a partir da sua experiência no campo da gestão social e das políticas públicas a partir de estudos sobre intersetorialidade e redes.

campo de estudo da gestão social, que se encontrava em construção ou in progress (Boullosa, 2009), ganhou maturidade e expandiu-se como objeto e processo de gestão tanto na academia quanto nas práticas de gestão das organizações da sociedade civil e da gestão das políticas públicas.

Para Inojosa e Junqueira (2008), a gestão social é entendida como a gestão "das políticas públicas que têm por objetivo regular o acesso das pessoas às riquezas materiais e imateriais da sociedade, de acordo com uma visão datada e localizada, isto é, no tempo e no espaço" (p. 172).

A ampliação na agenda de pesquisadores e de universidades surgiu dos estudos de vanguarda sobre gestão social e, dessa forma, 
INTERSETORIALIDADE E REDES: A TRAJETÓRIA DE LUCIANO ANTONIO PRATES JUNQUEIRA NA GESTÃO SOCIAL

pesquisadores de diversas áreas encontraram na gestão social um campo a ser construído em busca de respostas que as teorias já existentes de Administração e Administração Pública não eram capazes de responder.

A gestão social surge dentro dos templos universitários como possibilidade inovadora de pesquisa e ensino no campo da Administração. Passa-se a trabalhar com releituras de conceitos valorizando as contemporâneas práticas que buscam a inovação e mudança social, e as novas estratégias de intervenção para o desenvolvimento, de modo que muitas vezes não trabalhem com análises de elementos estruturais do sistema, não alterem modelos produtivos nem modos de distribuição de renda e de universalização de direitos. (Araújo, 2012, p. 33)

França (2008) adverte que a gestão social "parece constituir nos últimos anos um daqueles termos que tem conquistado uma visibilidade cada vez maior, tanto do ponto de vista acadêmico, quanto, sobretudo, em termos mediáticos" (p. 26).

Quanto aos participantes das discussões precursoras sobre a gestão social, Araújo (2012) destaca a produção de professores como Ladislau Dowbor (PUC-SP), Tania Fischer (UFBA), Fernando Tenório (FGV-RJ), Luciano Junqueira (PUC-SP), Genauto França (UFBA) e Rosinha Machado Carrion (UFRGS), trazendo visões diferenciadas em termos de ampliação da temática, principalmente no que diz respeito ao combate à pobreza, garantia dos direitos de cidadania e promoção do desenvolvimento, como focos centrais que a gestão social deve ter.
Desses pesquisadores, três, Tania Fischer (UFBA), Fernando Tenório (FGV-RJ) e Luciano Junqueira (PUC-SP), são comumente referenciados como os "papas" da gestão social, tendo cada um deles construído um caminho particular sobre a gestão social.

Luciano, Tania e Tenório já possuíam seus projetos interdisciplinares de estudos. Mesmo estando os três na macro área de administração, eles já estavam agregando pessoas ao redor e estudando esses temas. [...] Luciano trabalhava com terceiro setor, Tania, com poder local, e Tenório, com democracia deliberativa. A gestão social é apropriada nos grupos de pesquisa até chegar um ponto que eles se encontram de novo, mesmo que não seja um encontro físico, já nasce com esta tríplice interpretação: a gestão social, como gestão social dos territórios, com Tania; a gestão do terceiro setor, com Luciano; e a gestão não estratégica, democrática e dialógica, de Tenório. Esse momento é muito importante e fixa os três como cabeças de chave. (Boullosa, 2018)

Nesse contexto, esta pesquisa tem como objetivo analisar como a construção de um novo campo de estudos e a consolidação de um intelectual se dão de maneira simultânea. Para isso, optou-se por trabalhar a obra de Luciano Antonio Prates Junqueira, professor e pesquisador na PUC-SP há aproximadamente 35 anos, e, em especial, os conceitos de intersetorialidade e redes sociais que se constituíram como quase unanimidade, ao se observarem os trabalhos no campo da gestão social para as temáticas afins por ele elaborados.

A escolha desse intelectual foi motivada 
pelo fato de os autores acompanharem o cotidiano de trabalho desse professor e pesquisador e, a partir dessa vivência, ter sido possível perceber o vínculo existente entre a sua trajetória como agente social e o campo da gestão social, delimitado nesta pesquisa pelos pesquisadores da Rede de

Quadro 1. Pesquisadores entrevistados
Gestão Social (RGS).

Como metodologia, foram realizadas entrevistas com roteiro livre, com seis pesquisadores da RGS reconhecidos como referências no campo da gestão social (Quadro 1):

\begin{tabular}{|l|l|}
\hline Pesquisador & Universidade \\
\hline Edgilson Tavares de Araújo & Universidade Federal do Recôncavo Baiano \\
\hline Edson Sadao lizuka & Faculdade de Engenharia e Indústria \\
\hline Jeová Torres Silva Junior & Universidade Federal do Cariri \\
\hline Paula Schommer & Universidade Estadual de Santa Catarina \\
\hline Rosana Boullosa & Universidade Federal da Bahia \\
\hline Rosinha Machado Carrion & Universidade Federal do Rio Grande do Sul \\
\hline
\end{tabular}

As entrevistas foram gravadas e transcritas, e, em todas elas, os pesquisadores apresentaram suas vivências e impressões sobre o professor Luciano Antonio Prates Junqueira, analisando sua obra e sua influência intelectual tanto do ponto de vista teórico quanto como agente social.

Foi feita ainda uma entrevista em profundidade com a técnica de história de vida com o professor Luciano, que permitiu a visualização do panorama compreendido desde sua formação na graduação até o presente momento, possibilitando, dessa forma, maior compreensão da sua história. Em virtude da dimensão dos fatos narrados, tal conversa foi efetuada em dois momentos, totalizando mais de quatro horas de gravação.

Além disso, foi realizado um estudo das citações de Junqueira referenciadas na plataforma do Spell, na qual foram identificados 37 artigos, em uma linha do tempo que cobre de 2011 a 2018, citando 15 textos diferentes de Junqueira, conforme Quadro 2, mais adiante.

\section{O PAPEL DO INTELECTUAL}

Em 2010, houve o primeiro contato dos autores deste artigo com o livro Representações do intelectual, de Edward Said (2005), que cria, nessa obra, um argumento em que define o papel público do intelectual como um outsider, um amador e um perturbador do status quo. Uma das tarefas do intelectual reside no esforço em derrubar os estereótipos e as categorias redutoras que tanto limitam o pensamento humano e a comunicação.

Naquele momento, houve a conexão entre o professor Luciano Junqueira e seu papel como intelectual. Essa relação foi feita, mas ficou guardada até 2017, quando houve mais um elemento provocador, que foi a reflexão histórica sobre os 10 anos de Enapegs, como importante promotor da gestão social que progressivamente vem ganhando corpo e espaço para a produção de conhecimento. Assim, o estímulo para esta pesquisa encon- 
INTERSETORIALIDADE E REDES: A TRAJETÓRIA DE LUCIANO ANTONIO PRATES JUNQUEIRA NA GESTÃO SOCIAL

trava-se pronto e disponível.

Para Said (2005), o intelectual é um indivíduo com um papel público na sociedade, que não pode ser reduzido simplesmente a um profissional sem rosto, mas, sim, dotado de uma vocação para representar, dar corpo e articular uma mensagem, um ponto de vista, uma atitude, filosofia ou opinião para (e, também, por) um público.

O intelectual, no sentido proposto por Said (2005) não é nem um pacificador nem um criador de consensos, mas alguém que empenha o senso crítico, na recusa em aceitar fórmulas fáceis ou clichês prontos.

O que o intelectual menos deveria fazer é atuar para que seu público se sinta bem: o importante é causar embaraço, ser do contra e até desagradável. [...] Alguém que visivelmente representa um certo ponto de vista, e alguém que articula representações a um público, apesar de todos os tipos de barreiras. [...] E vocação é importante na medida em que é reconhecível publicamente e envolve, ao mesmo tempo, compromisso e risco, ousadia e vulnerabilidade. (p. 27)

Os intelectuais pertencem ao seu tempo e, para Said (2005), o objetivo da atividade intelectual é promover a liberdade humana e conhecimento, por meio de narrativas de emancipação e esclarecimento.

Para Foucault (2008), não basta ao intelectual expressar o lugar-comum que a população compreende e em que atua, e também não basta se colocar pouco à frente, com uma contribuição limitada em seus estudos e pesquisas. $O$ intelectual, a partir de seus estudos e aprendizados, pode se opor de maneira articulada e consistente às formas de poder vigentes, às verdades que, muitas vezes, são lugar-comum e aos discursos que as elaboram e sustentam. $O$ autor propõe que, para lutar de modo consistente contra as incoerências e desigualdades presentes na vida humana em sociedade, não basta se propor a desenvolver uma totalização teórica da dita verdade, mas, sim, a partir do entendimento do sistema de poder presente, combatê-lo também a partir de suas formas de exercício e aplicação.

Ambos os autores, Said e Foucault, ainda que possuam visões particulares sobre 0 papel do intelectual, não o entendem apenas como um repositório de informações e conhecimento ou como alguém a realizar estudos que sustentem e promovam a relação de poder existente. A partir de seu ponto de vista, privilegiado por esse conhecimento, o intelectual também pode atuar a partir de um ponto de vista privilegiado, a ele é permitido criticar e elaborar novas perspectivas para transformar a existência humana individual e em sociedade. Não é uma posição conservadora, que defende a realidade tal como ela se encontra, mas que desafia os pressupostos dados como certos por muitos.

Corá e Motta (2019), ao descreverem a trajetória intelectual de Luciano Antonio Prates Junqueira, destacaram suas contribuições como intelectual. Junqueira, ao longo de sua longa e produtiva trajetória acadêmica e profissional, demonstra o papel que um intelectual pode exercer tal como elaborado por Said e Foucault. Não apenas adquiriu conhecimento e ensinou a um grande número de alunos de graduação e pós, como tam- 
bém não aceitou verdades prontas e construiu novas perspectivas, novos saberes, que modificaram o entendimento do próprio e daqueles que conviveram e convivem com ele, em especial nos seus principais interesses de pesquisa, a intersetorialidade e as redes.

\section{TRAJETÓRIA DE VIDA DE LUCIANO AN- TONIO PRATES JUNQUEIRA}

Luciano Antonio Prates Junqueira, nascido em Minas Gerais, possui graduação em Ciências Sociais pela Universidade de São Paulo (1969), graduação em Filosofia pelo Studium Generale Santo Alberto Magno (1962), mestrado em Saúde Pública pela Universidade de São Paulo (1979) e doutorado em Administração da Saúde pela Universidade de São Paulo (1996). É professor titular da PUC-SP, universidade em que ingressou em 1981, coordenando, hoje, o Núcleo de Estudos Avançados do Terceiro Setor (NEATS/PUC-SP). De 1976 a 1998, trabalhou na Fundação de Amparo Administrativo (Fundap), ligada ao governo estadual, em que atuou como consultor em políticas públicas.

Essa é uma síntese do currículo, mas que não conta toda a trajetória vivida por Junqueira e suas relações firmadas profissionalmente e intelectualmente, buscando apenas fazer um relato dos principais pontos de intersecção entre a trajetória de vida e a gestão social.

Entendo o Luciano como um grande intelectual. É um grande intelectual da administração pública, na verdade, com papel fundamental na área de redes, de intersetorialidade da gestão pública. De fato, ele colaborou como intelectual orgânico, principalmente porque ele foi uma pessoa que sempre se preocupou em desenvolver um conhecimento situado, conhecimento útil, um conhecimento aplicado. E que é algo raro, também na academia, muitas vezes porque as pessoas ficam muito mais preocupadas na construção teórica pela construção teórica, sem necessariamente experimentar aplicar. Acho que é essa característica fundamental dele: a aplicação do conhecimento. (Araújo, 2018) ${ }^{3}$

A contribuição do Luciano com intersetorialidade e redes vem lá do passado vinculada à gestão pública e à saúde, em que ele percebe a insuficiência de política pública sem trazer a intersetorialidade e redes. Assim, essa foi a temática, a partir da relação dele com a administração pública, com a saúde, com a Fundap, pois naquele momento as políticas estavam muito separadas, mas para acontecer elas tinham que interagir de forma intersetorial. Essas temáticas são de longo prazo e isso traz uma identidade. [...] E, de onde vem? Vem da preocupação com a questão social, preocupação com o outro, entender outras lógicas, outras possibilidades. (lizuka, 2018) ${ }^{4}$

Sempre interessado em pesquisa, quando estudante de graduação de Ciências Sociais, trabalhou na pesquisa "Origem e destino do metrô", no início da década de 1970. Quando se formou em Ciências Sociais, trabalhou no Plano de Amparo Social (PAS), uma fundação pública, sendo demitido na época da ditadura militar, por ser considerado subversivo, quando estava trabalhando na pesquisa "Marginalidade social no estado de São Paulo". 
INTERSETORIALIDADE E REDES: A TRAJETÓRIA DE LUCIANO ANTONIO PRATES JUNQUEIRA NA GESTÃO SOCIAL

Após esse episódio, ele foi indicado para trabalhar numa pesquisa na área de saúde, primeiramente na Secretaria de Saúde do Estado de São Paulo e, em seguida, para a Faculdade de Saúde Pública da USP, na qual, mais uma vez, foi impedido de ingressar na carreira docente.

No Centro Nacional de Formação Profissional (Cenafor), Luciano passou a trabalhar como consultor em uma pesquisa nacional de avaliação de escolas agrícolas e, após um ano e meio, quando seria contratado, foi impedido de ingressar na carreira.

Diante desse contexto político, Luciano começou a procurar outros espaços de pesquisa para que conseguisse trabalhar. $\mathrm{Pa}-$ ralelamente, em 1976, estava sendo criada a Fundap, que tinha três eixos: pesquisa, formação e consultoria. Mesmo tendo interesse na área de pesquisa, acabou ingressando na área de consultoria.

Ali, passou por treinamento na área de consultoria e um ano de treinamento em pesquisa-ação, e seu primeiro projeto foi uma consultoria de reforma administrativa na $\mathrm{Pi}$ nacoteca do Estado de São Paulo.

$\mathrm{Na}$ Fundap, foram criados quatro núcleos de áreas fins, e um deles era saúde, núcleo que ele passou a coordenar. Assim, começou, de maneira pontual e vigorosa, a sua inserção na área da saúde, com consultorias, cursos de formação, e, nesse processo, Luciano criou e consolidou relações de ordem técnica com profissionais da saúde pública.

Conseguiu pactuar projetos na Secretaria de Saúde durante o governo Montoro, sendo um período bastante enriquecedor, viajando por todo o Brasil replicando as experiências aprendidas, merecendo destaque os trabaIhos realizados como consultor no governo do Espírito Santo e também na Secretaria Estadual de Saúde do Ceará e, depois, especificamente, na prefeitura de Fortaleza.

O Luciano tinha uma trajetória pesada nas políticas pública, da saúde e de organizações; ele tem uma vivência de campo ao lado da construção teórica e, por isso, nós sempre o alocamos nas discussões de rede, por conta da sua experiência. (Silva, 2018)

$\mathrm{Na}$ consultoria junto à prefeitura de Fortaleza, foi convidado para desenvolver algo inovador, o que favoreceu o surgimento do conceito de intersetorialidade, pensando na reformulação da gestão da prefeitura a partir da gestão das políticas públicas em si. Assim, foi proposta uma inovação, pois, como o próprio Luciano afirmou: "Eu acho interessante ter uma coisa nova, as coisas não precisam ser feitas da mesma forma sempre".

No período de transição entre os mandatos, o prefeito de Fortaleza aceitou o desafio e participou ativamente do projeto, havendo adesão de boa parte dos gestores públicos. O projeto acabaria com as secretarias municipais específicas e, no lugar, seriam criadas secretarias mais amplas, focando o trabalho em equipes interdisciplinares.

Toda essa (des)construção foi discutida na Câmara dos Vereadores e com os novos secretários; além disso, eram realizadas reuniões abertas nas Unidades de Gestão da cidade com intensa participação da sociedade. Assim, foi criada a Secretaria de 
Desenvolvimento Social, em que havia uma ação intersecretarial da Saúde, da Assistência Social e da Educação para realizar uma gestão integrada.

O projeto nuclear era a intersetorialidade, de modo que o conceito da interdisciplinaridade passasse a ser uma prática e que toda a relação constituída para a execução de políticas públicas se desse dessa forma.

Após a finalização da consultoria, por questões políticas, o prefeito, mesmo acreditando no projeto, teve que regredir em algumas das suas iniciativas, mas, do ponto de vista intelectual, para Luciano, essa experiência garantiu uma discussão teórica de diferentes visões, considerando o SUS como um norteador, já que ele sempre buscou essa intersetorialidade como uma prática dinâmica.

Do estudo de intersetorialidade, como uma oportunidade de gestão integrada, passar para a perspectiva de redes foi um pulo, pois, nos dois casos, os estudos passavam pela construção das relações em todo o ciclo das políticas públicas - elaboração, implementação e avaliação, propondo uma gestão integrada dessas políticas e, por isso, a perspectiva de redes é importante para viabilizar a intersetorialidade.

Em paralelo ao trabalho na Fundap, Luciano começou a sua carreira de docente na PUC-SP, ministrando a disciplina "Metodologia de pesquisa", nos cursos de Administração e Economia, no começo da década de 1980 , acumulando os dois espaços de trabalho, a Fundap, com as consultorias, e a PUC-SP, com a docência.
No final dos anos 1990, com a redução dos projetos de consultoria da saúde realizados pela Fundap, as demandas de trabalho passaram a ser de várias áreas, acabando por ser pouco motivadoras para Luciano, situação que culminou com a sua adesão ao Programa de Demissão Voluntária, em 1998. Nesse momento, Luciano foi dedicar-se à vida acadêmica na PUC-SP.

A trajetória de Luciano na PUC-SP destaca-se pela aplicação do tripé universitário: sempre atuou na pesquisa, ensino e extensão, tanto na pós-graduação quanto na graduação, tendo sublinhado seu papel como orientador de pesquisa de iniciação científica, mestrado e, posteriormente, doutorado.

Institucionalmente, buscava a construção do conhecimento interdisciplinar, relacionando com outros programas de pós-graduação, como economia, contabilidade, ciências sociais, psicologia social, serviço social, educação e currículo, entre outros. Outra característica foi se aproximar de outras universidades para criar espaços de troca e compartilhamento de experiências.

O tempo que estive como professor na pós-graduação percebi que o Luciano, como intelectual, como professor, como profissional, tinha que lutar contra tudo e contra todos para fazer as coisas acontecerem na pós-graduação, dentro do programa um dos caras que mais fez para tornar a pós graduação melhor, fui testemunha da luta dele. Ele lutava para manter a identidade da PUC e se aproximar de coisas que ele via em outros programas. Ele não fica só no âmbito das palavras, ele é coerente quanto suas atitudes. (lizuka, 2018) 
INTERSETORIALIDADE E REDES: A TRAJETÓRIA DE LUCIANO ANTONIO PRATES JUNQUEIRA NA GESTÃO SOCIAL

Um dos grandes feitos de Luciano foi assumir o Núcleo de Estudos Avançados de Terceiro Setor (Neats). Inicialmente o núcleo foi fundado por estudantes, com o apoio do professor Ladislau Dowbor, porém, quando Luciano ingressa no Programa de Pós- Graduação, é convidado para participar no núcleo, incumbindo-se, logo em seguida, da sua coordenação.

Nesse momento, a agenda de estudos no âmbito do terceiro setor ainda era bastante incipiente, com iniciativas isoladas de pesquisadores em diversas universidades, e os estudantes, também sentindo essas ausências, impulsionaram encontros entre os pesquisadores, por exemplo, com o Prêmio Fenead $^{5}$.

O Prêmio Fenead acabou por impulsionar o encontro destes professores, eles estavam cada um com sua agenda, mas os estudantes de alguma forma deram evidência aos professores que tinham mais compromisso com o social, que estavam mais interessados com uma gestão que não fosse a gestão tradicional. É nessa hora que o Luciano aparece, o Merege, a Rosinha, esses professores estavam fazendo suas agendas isoladamente, e o Prêmio Fenead foi o catalisador dos núcleos de estudos sobre o terceiro setor no país. (lizuka, 2018)

À frente do Neats, Luciano foi consolidando os trabalhos no núcleo, agregando novos pesquisadores e docentes e, em 2000, iniciou os preparativos para a realização do Congresso de Voluntariado, trabalhando durante um ano na construção de relações com as organizações do terceiro setor com apoio da pesquisadora Ana Maria Domene- ghetti. O Congresso de Voluntariado ocorreu em 2001 e teve mais de 700 participantes, dando visibilidade nacional ao Neats.

O Luciano era um pioneiro. A primeira vez que tive contato com ele, foi num encontro na PUC, que ele fez sobre terceiro setor e voluntariado [...] e fiquei muito impressionada, pensei que o Luciano era um pioneiro que conseguiu organizar um evento bem significativo que tratava de temais ainda marginais na gestão. (Schommer, 2018) ${ }^{6}$

Após o Congresso de Voluntariado, o Neats passou a ter uma proposta de expansão de atuação, trazendo novos pesquisadores, criando espaços de escuta da prática das organizações do terceiro setor, fortalecendo as pesquisas realizadas nesse campo de conhecimento. Nesse contexto, a PUC-SP, por meio do Neats e do Luciano, foi assumindo um papel de referência em pesquisa de assuntos voltados ao terceiro setor, junto com a FGV e a USP, logo, quem se interessasse por essa temática acabava buscando uma das três instituições para realização e aprofundamento de estudos a ela relacionados.

Uma característica de Luciano é que ele é um impulsionador de novos pesquisadores e novos atores. Essa referência é bastante forte, pois ele acredita que todos os interessados devem ser estimulados a conquistar seus anseios, ainda mais em um espaço em construção como o terceiro setor e a gestão social.

Quando eu era recém-formado, garoto, ele me chamou para dar um curso. Eu não tenho nenhuma dúvida de que ele me im- 
pulsionou, que me jogou para frente e me incentivou. Se não fosse o Luciano, primeiro estabelecendo contato, fazendo a ponte para eu dar o curso, eu talvez hoje estivesse com outra carreira, então eu acho que ele foi, sem dúvida, uma primeira porta de entrada na carreira docente e como pesquisador. (lizuka, 2018)

Com isso, muitas vezes ele quebra as regras, as convenções que a academia espera de um professor titular, pois, quando ele vê que algo é substantivo, que é importante e ele acredita, faz acontecer.

Luciano ainda destaca sua participação na Anpad, no subgrupo de Administração Pública, como fundamental para construir parcerias com outras universidades e, principalmente, com pesquisadores do campo da gestão pública, publicando diversos números de revistas temáticas e fortalecendo a visibilidade das pesquisas do Neats e, consequentemente, da PUC-SP no campo de pesquisa.

A RGS começou a ser desenhada em 2003 e, desde então, vem desenvolvendo discussões a partir de uma agenda pautada na gestão de problemas sociais e ambientais, por meio de articulações democráticas e mediante uma visão intersetorial e interorganizacional. Nesse sentido, todos os entrevistados afirmaram que o papel do Luciano é fundamental para a consolidação da RGS:

Para mim é fundamental, prova disso que, para fazer o primeiro ENAPEGS ${ }^{7}$ aqui no Cariri, Luciano foi o terceiro nome que falei. E ele foi bem solícito, na hora já pudemos contar que ele vinha. (Silva Junior, 2018)
Luciano, na Rede de Gestão Social, é uma pessoa que consegue colocar o freio necessário em algumas discussões, [...] as pessoas entendem seus freios porque ele é respeitado. Então ele consegue puxar a cordinha quando a gente está devaneando demais. Ele também é um ser aglutinador, ele consegue, por exemplo, fazer com que as pessoas estabeleçam determinado consenso com relação a práticas dentro da rede. Acho que isso é muito do perfil dele, enquanto profissional, talvez até uma coisa da própria sabedoria da experiência de vida. (Araújo, 2018)

O Luciano é uma linha de continuidade que garante legitimidade, alguém que acompanha essa história desde o início, e ele legitima a construção do campo pela própria presença. Uma presença generosa, reflexiva e que ajuda os pesquisadores mais novos a se desenvolver nessa área, estimulando e abrindo espaço e oportunidade, sempre estando presente. (Schommer, 2018)

Luciano foi se tornando, além de uma referência teórica, uma força centrípeta dentro da gestão social. É bom estar com ele, ele agrega a segunda geração de pesquisadores, que é o Jeová, Paula, Edgilson, Airton, Rosinha e uma terceira geração que sou eu, Valéria [...] Eu vejo a importância de Luciano assim, faz parte da história da gestão social e ele dá leveza à discussão. O Luciano faz um contraponto em que a intersetorialidade é um instrumento de gestão e um instrumento de análise. (Boullosa, 2018)

Nas discussões que tivemos sobre a Rede, 
INTERSETORIALIDADE E REDES: A TRAJETÓRIA DE LUCIANO ANTONIO PRATES JUNQUEIRA NA GESTÃO SOCIAL

se seria formalizada ou não, ele trouxe o aporte da experiência, não só da vivência, mas também teórico-conceitual, e essa base conceitual de pesquisa empírica nos iluminou nas nossas próprias discussões sobre a rede de pesquisadores. (Schommer, 2018)

Como apontado pelos entrevistados, as intervenções de Luciano para o debate da RGS foram decisivas para sua consolidação no formato em que se encontra hoje, tanto nas intervenções como pesquisador do tema quanto para agente de atuação em rede.

Em maio de 2012, o Enapegs foi realizado em São Paulo, sob a coordenação de Luciano, com a participação, além da PUC-SP, como proponente, de docentes da USP e da FEl. O evento contou com mais de 350 participantes, 200 trabalhos apresentados, com participação de palestrantes de referência nacional e internacional no campo, além de uma aproximação efetiva dos docentes e pesquisadores do curso de Serviço Social da PUC-SP.

No final do Enapegs, fizemos uma homenagem ao Luciano, pois foi incrível perceber como o evento foi tão bacana, envolvendo tanta gente, de tantas instituições e com todos comprometidos [...] E o Luciano era aquela figura que estava à frente, e, ao mesmo tempo, ele não se coloca como o líder, o principal, embora ele seja, porém ele faz todos serem protagonistas. Isso reflete bastante o espírito da gestão social, do nosso campo, que é baseado numa construção coletiva, da amizade, do ouvir mais do que falar. Assim, ele encarna o próprio sentido que a gente identifica como gestão social. (Shommer, 2018)

Temos no Luciano o principal interlocutor, e sabemos que, se as coisas estão bem, elas devem estar bem com ele, pois ele é uma referência como pessoa. (Silva Junior, 2018)

Pesquisando sobre a trajetória de Luciano, na perspectiva dos outros pesquisadores da gestão social, fica bastante evidente que ele tem uma presença significativa, tanto na constituição da história da Rede, quanto nos projetos futuros dos pesquisadores, isso porque Luciano constituiu laços fortes (Granoveter, 1973), dando segurança e legitimidade para os envolvidos, como também construindo relações afetivas consolidadas.

Eu entendo que Luciano tem um papel, muito mais que uma referência histórica, em termos de defesa de valores, de novas possibilidades, de ser o mais humanizado. Então, quando eu digo que ele é uma referência histórica, é porque ele é uma pessoa que carrega consigo o papel de transmitir valores da gestão social. Acho que isso é algo muito significativo na trajetória dele. [...] Luciano está muito relacionado ao carisma, a esse poder de agregar as pessoas, também de polemizar quando tem que polemizar e de parar determinadas discussões que muitas vezes não levam a lugar nenhum. (Araújo, 2018)

Ele tem um jeito de ser que é muito doce, muito amigo, diferente de muitos que a gente vê na academia. Eu me recordo do evento de 2012, quando ele coloca os colegas mais à frente, como protagonistas. Não sei se para ele o conceito de liderança servidora é o termo correto, mas é esse 
líder que está sempre ali permitindo que as pessoas desenvolvam seu potencial, que assumam seu protagonismo e ele se coloca mais como um servidor do que um autor principal, mas na verdade ele está o tempo todo orquestrando, não sei se deliberadamente ou naturalmente, mas ele faz isso. Ele nos dá a segurança de que estamos seguindo o correto. (Schommer, 2018)

Luciano pode discordar quando todos acham que ele deve concordar, ele se permite. Eu acho que é uma relação mais franca com a história e o presente, pois, nesse caso, a história e o presente dialogam. [...] O Luciano tem essa liberdade para com ele, e isso é inspirador. (Boullosa, 2018)

Percebo a presença dele quase como um cimento, como um elo, como uma pessoa capaz de entrar naqueles meandros perdidos, tendo uma capilaridade que consegue chegar e reunir, e trazer de forma harmoniosa. Percebo o Luciano como uma pessoa capaz de agregar e extremamente sagaz. Ele mescla essas características com uma ternura nas relações pessoais [...] ele consegue dar uma alfinetada para trazer de volta o bom senso e sair do campo da crítica. (Carrion, 2018)
Ele tem posição, crítica e tenta fazer da forma dele, uma forma mineira, simpática que ele sempre teve, e ele adora dar uma chacoalhada nas coisas. Ele também sempre foi muito perspicaz sabendo a hora de falar. (lizuka, 2018)

Os valores pessoais de Luciano aparecem como características essenciais para fazer dele um intelectual conforme proposto por Said. Ele promove o saber, mesmo quando isso significa tirar da ordem, ser subversivo, ser sagaz, ou, como Boullosa afirma, ter a liberdade de se posicionar conforme sua história e seu presente, sem que isso o impeça de criar outras frentes de trabalho e de defender posturas nas quais acredita.

\section{PRODUÇÃO TEÓRICA}

Para análise da produção teórica do intelectual, foram selecionadas duas temáticas recorrentes nas pesquisas realizadas por Junqueira, intersetorialidade e redes sociais, além da própria conceituação da gestão social.

A partir de uma análise de conteúdo das citações referenciadas pelo Spell, identificaram-se 37 artigos, em um horizonte temporal de 2011 a 2018, dos quais foram citados 15 textos diferentes de Junqueira, conforme Quadro 2: 
INTERSETORIALIDADE E REDES: A TRAJETÓRIA DE LUCIANO ANTONIO PRATES JUNQUEIRA NA GESTÃO SOCIAL

\section{Quadro 2. Citações de obras de Luciano Junqueira}

\section{Artigo}

Junqueira, L. A. P. (2000, Novembro/Dezembro). Intersetorialidade, transetorialidade e redes sociais na saúde. Revista de Administração Pública, 34(6), 35-45.

Pinto, A. M. G., \& Junqueira, L. A. P. (2009). Relações de poder em uma rede do terceiro setor: Um estudo de caso. Revista de Administração Pública, 43(5), 1091-1116.

Junqueira, L. A. P., Maior, J. S., \& Pinheiro, F. P. (2011). Sustentabilidade: A produção científica brasileira entre os anos de 2000 e 2009. Revista de Gestão Social e Ambiental - RGSA, 5(3), 36-52.

Mendonça, P. M., Gonçalves-Dias, S. L. F., \& Junqueira, L. A. P. (2012, Setembro/Outubro). Gestão social: Notícias sobre o campo de estudos e práticas a partir das interações e debates do VI Enapegs. Revista Administração Pública, 46(5), 1391-1408.

Junqueira, L. A. P. (2004). Gestão intersetorial das políticas sociais e o terceiro setor. Saúde e Sociedade, 13(1), 25-36.

Inojosa, R. M., \& Junqueira, L. A. P. (2008). Práticas e saberes: Desafios e inovações em gestão social. Organização \& Sociedade, 15(45), 171-180.

Junqueira, L. A. P. (2008). Gestão social: Organização, parceria e redes sociais. In A. C. Cançado et al. J. T. Silva Junior, P. C. Schommer, A. S. Rigo. Os desafios da formação em gestão social (pp. 87-103). Palmas, TO: Provisão.

Junqueira, L. A. P. (2006). Organizações sem fins lucrativos e redes sociais na gestão das políticas sociais. In M. Cavalcanti (Org.), Gestão social, estratégias e parcerias: Redescobrindo a essência da administração para o terceiro setor (Vol. 1, pp. 195-218). São Paulo, SP: Saraiva. Junqueira, L. A. P., \& Misoczky, M. C. (2009). Redes sociais: Apresentação. Revista de Administração Pública, 43(5), 1003-1005.

Faro, E. S. C., Amorim, M. C. S., Trevisan, L., \& Junqueira, L. A. P. (2010). Âncoras de carreira e transformações no modelo de administração: Estudo de caso do Tribunal de Contas da União (TCU). Cadernos EBAPE.BR, 8(4), 710-733.

Junqueira, L. A. P. (1998). Descentralização e intersetorialidade: A construção de um modelo de gestão municipal. Revista de Administração Pública, 32(2), 35-48.

Junqueira, L. A. P. (1999, Novembro). Descentralização, intersetorialidade e rede como estratégias de gestão da cidade. Revista FEA-PUC-SP, 1, 57-72.

Junqueira, L. A. P. (2006, Novembro/Dezembro). Porto e meio ambiente. Revista Administração Pública, 40(6), 971-973. Recuperado de http://www.scielo.br/ pdf/rap/v40n6/02.pdf Junqueira, L. A. P. (2002). Trabalho voluntário e gestão das políticas sociais. In C. Perez, \& L. A. P. Junqueira (Orgs.), Voluntariado e gestão das políticas sociais (Vol. 1, pp. 136-147). São Paulo, SP: Editora Futura.

Sousa, M. R., Junqueira, L. A. P., \& Casas, A. L. Las. (2014). O perfil do franqueado divulgado pelos franqueadores na fase de prospecção de candidatos. Revista Organizações em Contexto-online, 10(19), 213-243. 
Observa-se que as obras mais citadas estão alinhadas aos temas de intersetorialidade, redes sociais e gestão social, destacando-se do ponto de vista da construção teórica das três temáticas.

Em relação à consolidação de conceitos que permeiam a gestão social anunciada e vislumbrada por Junqueira, aparece como mediadora e articuladora de processos intersetoriais voltados para a superação dos problemas públicos, na qual "o deslocamento do poder de decisão é um meio para democratizar a gestão via participação, apontando para a redefinição da relação Estado e sociedade" (Araújo, 2019, p. 93).

Araújo (2018), em sua entrevista, ainda reitera a importância de se trazer o debate da intersetorialidade no percurso teórico de Luciano Junqueira: "para além da ser uma referência histórica do campo da gestão social, Luciano tem uma pesquisa profunda, do ponto de vista teórico, sobre uma das principais bases do conceito de gestão social que é o conceito de intersetorialidade, ele estuda as relações entre Estado e sociedade civil".

Sobre essa dimensão, cabe destacar o conceito de Junqueira (2004) a respeito da intersetorialidade como:

um processo de aprendizagem e de determinação dos sujeitos, que deve resultar em uma gestão integrada, capaz de responder com eficácia à solução dos problemas da população de um determinado território, saindo, entretanto, do âmbito da necessidade para o da liberdade. O homem é considerado na sua integralidade, superando a autonomização e a fragmen- tação que têm caracterizado a gestão das políticas sociais para uma dimensão intersetorial. (p. 26)

A ação intersetorial propiciada pela gestão social traz, portanto, uma nova lógica de superação da fragmentação das políticas, considerando o cidadão em sua totalidade, já que estabelece novas relações sociais (Junqueira, 2004, 2008). A gestão social é, por conseguinte, mediadora e articuladora de processos intersetoriais voltados para o desenvolvimento e superação da exclusão (Araújo, 2012). E, ainda, como enfatiza Luciano:

Essa nova realidade que está sendo construída estabelece uma nova relação entre Estado e sociedade, entre público e privado. Até período recente, o Estado era o promotor exclusivo das políticas sociais, mas essa situação começou a mudar em função das demandas e das pressões advindas de pessoas e grupos organizados, até mesmo dos organismos governamentais que buscam novas formas de gestão, novas maneiras de atender às necessidades sociais. (Junqueira, 2006, p. 198)

Essa perspectiva interage diretamente com a noção de rede em que os objetivos são definidos coletivamente, articulam pessoas e instituições que se comprometem a superar de maneira integrada os problemas sociais. Essas redes são construídas entre seres sociais autônomos, que compartilham objetivos os quais orientam sua ação, respeitando a autonomia e as diferenças de cada membro. Daí a importância de que cada organização pública - estatal ou privada - desenvolva seu saber para colocá-lo de maneira integrada a serviço do interesse coletivo (Junqueira, 


\section{INTERSETORIALIDADE E REDES: A TRAJETÓRIA DE LUCIANO ANTONIO PRATES JUNQUEIRA NA GESTÃO SOCIAL}

2000, p. 39).

Quanto a esse aspecto, Junqueira mantém a preocupação de trazer os elementos da intersetorialidade para a compreensão das redes sociais, pois, segundo o pensamento que o orienta, a relação que se estabelece entre pessoas, Estado e organizações é parte de uma ação mais integrada com o ambiente e, sobretudo, na busca do bem comum, respeitando o saber e a autonomia de cada membro da rede, redesenhando os papéis do primeiro, segundo e terceiro setores.

O conceito de terceiro setor, pujante naquele contexto de expansão e profissionalização das organizações da sociedade civil, sem fins lucrativos, aparece como sendo composto de "organizações que envolvem pessoas comprometidas com o bem coletivo, onde a iniciativa individual não privilegia interesses individuais, mas coletivos.' Delega-se a essas a missão de releitura e ressignificação da sociedade civil, no sentido não de substituir, mas de colaborar com o Estado na implementação de políticas sociais, demandando destas abandonar antigas práticas de cunho assistencialista e caritativo, bem como assumir novos papéis quanto à complementaridade da ação estatal para a promoção dos direitos de cidadania. (Araújo, 2019, p. 92)

Nas redes, os objetivos definidos coletivamente articulam pessoas e instituições que se comprometem a superar, de maneira integrada, os problemas sociais.

Boullosa (2019), ao analisar o texto de Junqueira (2000), afirma:
Assumir rede como conceito fundamental para o estudo das políticas públicas significa diminuir a importância das estruturas formais do processo político-administrativo para dar lugar à rede de relações entre atores e coisas como constituidoras do inteiro processo de políticas públicas. Trata-se de uma profunda mudança, mesmo porque, ao fazer isso, o autor parece assumir também um certo caráter de projetação social e políticas em seu texto. (p. 64)

As redes empoderam seus participantes, pois elas vivem do fluxo das relações. Em um território, muitos atores podem articular-se em rede, mobilizados por visões e objetivos compartilhados, a fim de transformar situações. Redes acolhem entes autônomos, com suas identidades peculiares, para que, em um relacionamento horizontal, realizem ações com parceria, articulando múltiplos saberes, experiências e poderes, os quais tornam o conjunto mais apto para lidar com os complexos problemas apresentados à gestão social (Inojosa \& Junqueira, 2008, p. 178).

As redes de organizações mostram-se como um meio para intervir na realidade social existente, tornando possível a construção de estruturas que se organizam de tal forma que permitam que seja posta em prática a chamada gestão social.

Conforme menciona Junqueira (2004), "a intersetorialidade e a rede, para dar eficiência e eficácia à gestão das políticas sociais, exigem mudanças significativas na lógica da gestão para atender os interesses coletivos" (p. 25). Nesse sentido, poderiam ser reali- 
zadas mudanças dentro das organizações, dos sistemas, serviços e profissionais que atuam nas políticas públicas, com o objetivo de tornar o aparelho estatal mais ágil e eficaz.

É importante registrar que a intersetorialidade trazida por Junqueira está na raiz de outros conceitos-chave que se conformam como caminhos férteis para o estudo das políticas públicas no Brasil, como é o caso da transversalidade e da integração de saberes (Boullosa, 2019).

\section{CONSIDERAÇÕES FINAIS}

O papel do intelectual é promover o conhecimento e trazer uma ruptura do status quo, proporcionando novos debates e geração de ideias que possam significar um processo de aprendizagem.

Os dois conceitos, intersetorialidade e redes, tornaram-se referência na obra de Junqueira, sobretudo pelo fato de que ele, como agente social, atua articulando redes e propõe a intersetorialidade como projeto de promoção do conhecimento.

Mesmo ainda incipiente, este ensaio demonstra como um intelectual vai se consolidando junto com um campo de formação, principalmente quando o intelectual, além de estudar o conceito, pratica em suas relações cotidianas aquilo que estuda, comprovando como novas relações de redes são fundamentais para abertura de novos espaços do saber.

O que pode ser observado é que o conceito de intersetorialidade trabalhado por Luciano está muito enraizado em sua experiência como consultor de políticas públicas, especialmente na área da saúde. Essa relação entre a prática e a academia trouxe uma bagagem que fez os textos sobre o tema se tornarem referência nas áreas finalísticas de políticas sociais, principalmente na saúde pública e na assistência social.

Trabalhar em espaços nos quais era possível pôr em prática sua criatividade, como a Fundap e a PUC-SP, possibilitaram a Luciano as experimentações como pesquisador $e$ agente social, desde a coordenação de projetos inovadores para as políticas públicas, como a condução de modo interdisciplinar do Neats, a organização de congressos e encontros, até a prática docente nos programas de pós-graduação e de graduação que fizeram com que Luciano estivesse sempre em contato com novas agendas de pesquisa e de práticas sociais, tanto na gestão pública quanto nas organizações do terceiro setor.

Essas iniciativas sempre propiciaram e o conduziram para que colocasse em prática seus conceitos de interdisciplinaridade e a formação de redes na condução dos trabaIhos, como afirma Boullosa (2019) ao refletir que a obra de Junqueira "assume, assim, sem alarde, a não neutralidade da ciência e produz uma pesquisa implicada na transformação social, uma pesquisa que declara os seus valores e se abre para a construção social do conhecimento, sem a primazia da razão instrumentalizada" (p. 67).

Observou-se também, a partir das entrevistas realizadas, que Luciano ainda se constitui como uma forte referência para a segunda e terceira gerações de pesquisadores da RGS, muito mais em razão de seu papel como agente social do que por seus escritos. 
INTERSETORIALIDADE E REDES: A TRAJETÓRIA DE LUCIANO ANTONIO PRATES JUNQUEIRA NA GESTÃO SOCIAL

Quanto aos jovens pesquisadores, que se encontram em formação, esses desconhecem a obra e a pessoa de Luciano, demonstrando que há uma diversidade de novos autores de referência no campo da gestão social, provocando um distanciamento teórico das obras de Luciano.

Talvez isso se dê pelos diversos caminhos epistemológicos que os pesquisadores estão percorrendo no campo da gestão social, e pode haver baixa identificação com as temáticas por ele trabalhadas. $\mathrm{O}$ fato é que, em outros campos do conhecimento, como as áreas da saúde pública e assistência social, Luciano ainda é uma forte influência, participando de eventos e bancas com outros pesquisadores dessas áreas.

Para Sposati (2019), "Luciano Junqueira nos propôs um grande desafio, mas só agora se constata, e em grandes fatos e feitos, quantas tramas e linhas de força têm as redes sociais. Isso nos leva a pensar que tipos de redes sociais se tornam historicamente necessárias para que o sistema democrático de pesos e contrapesos possa continuar sua jornada" (p. 147).

Hierarquizando a trajetória intelectual de Luciano Junqueira no campo da gestão social, pode-se considerar que ele é um agente social de referência no campo, legitimado como intelectual sério, consistente e engajado, quanto às teorias de intersetorialidade e redes sociais que possuem destaque na gestão social, especialmente as áreas fins de políticas públicas, como a saúde e a assistência, porém sem se constituir como autor de referência dos pesquisadores em formação.
As características de personalidade e os valores pessoais de Luciano o tornam um laço que conecta os atores que atuam no campo da gestão social, respeitando as autonomias, os interesses por meio do afeto, do conhecimento e do respeito.

Nós temos um profundo respeito pelo Luciano, a influência que ele tem é de uma trajetória, alguém que a gente reconhece como uma história, é o respeito por esse homem Luciano: alguém que passou por momentos difíceis, mas é extremamente digno, com uma trajetória linda. Tudo que eu sei do Luciano, na realidade, é contado por ele mesmo e me inspira muita confiança. (Carrion, 2018)

Por fim, ainda se espera que Luciano continue sua trajetória pioneira, como o próprio Silva Junior (2018) afirma, quando justifica o convite feito a Luciano em participar do Enapegs 2018: "O Luciano ainda tem muito a oferecer, tanto que a experiência dele ainda é fundamental para a Rede."

Assim, encerram-se estas considerações, destacando a fala de lizuka (2018) que afirma que "o Luciano jamais é uma representação, o Luciano é o Luciano, é integro, é fiel aos princípios, as defesas que ele faz e a prática que ele tem. Ele não é uma pessoa que diz defender a democracia e a gestão social e tem uma atitude diferente disso, de forma alguma. É no cotidiano que você percebe os valores."

Dessa forma, Luciano Junqueira não apenas realizou mudanças discretas nos saberes das ciências sociais aplicadas no Brasil, como, a partir destes, questionou muitas vezes a realidade vigente e propôs alterna- 
tivas inovadoras para o papel do indivíduo em sociedade. Foi e é protagonista de um trabalho que se aproxima daquele intelectual aguerrido, questionador e comprometido com a mudança.

Ao lado de seu trabalho e pesquisa, em suas aulas e pesquisas, ao contribuir para a formação de outros intelectuais, pode estimular esse espírito questionador em gerações de acadêmicos por ele formados. Como ressaltaram Corá e Motta (2019), "Junqueira é uma catapulta para novos atores. Crê, de modo inequívoco, que todos os interessados em algo devem ser estimulados. Preconiza, na lida diária, os desejos que movem as pessoas e as organizações" (p. 17).

Faria e Meneghetti (2011) destacam intelectuais questionadores e que propuseram um pensamento inovador para compreender a complexa sociedade brasileira, acadêmicos da envergadura de Prestes Motta e Tragtenberg. Este artigo apresenta a trajetória de outro intelectual, com outros temas de pesquisa, que também nunca deixou de buscar inovar e questionar a realidade e assim promover mudanças, necessárias para o desenvolvimento nacional. Ainda que muitas vezes confrontada e questionada, a contribuição de Junqueira é perene, relevante e merece ser mais bem conhecida, para o desenvolvimento de próximas gerações de intelectuais e como ponto de partida para novas e arrojadas pesquisas acadêmicas.

E agora, falando pelos autores deste texto, viver o cotidiano com Luciano é um prazer, é uma prática de generosidade de compartilhamento de saberes e de afetos, com certeza sendo um intelectual que nos inspira na prática do saber; o que pode ser sintetiza- do como a trajetória e a obra de Luciano é aquilo que Deleuze indaga sobre o papel da teoria ao afirmar que "a teoria não se totaliza; a teoria se multiplica e multiplica" (Foucault, 2008, p. 71).

\section{REFERÊNCIAS}

Araújo, E. T. (2012). (In)consistências da gestão social e seus processos de formação: Um campo em construção (Tese de doutorado, Pontifícia Universidade Católica de São Paulo).

Araújo, E. T. (2019). Intersetorialidade: A gestão social anunciada por um intelectual Visionário. In M. A. J. Corá, \& R. G. Motta (Org.), Intersetorialidade e redes: A trajetória do intelectual Luciano Antonio Prates Junqueira. São Paulo, SP: Labrador, 89-94.

Boullosa, R. F. (2009). Contribuições conceituais e metodológicas para a avaliação de processos e práticas de gestão social a partir das perspectivas da policy analysis e da abordagem social da aprendizagem. XI Colóquio Internacional sobre Poder Local, CIAGS/UFBA, Salvador, BA.

Boullosa, R. F. (2019). A contribuição de Luciano Junqueira para o campo de estudos em políticas públicas no Brasil: Redes, intersetorialidade e a natureza projetada dos objetos de pesquisa. In M. A. J. Corá, \& R. G. Motta (Orgs.), Intersetorialidade e redes: A trajetória do intelectual Luciano Antonio Prates Junqueira. São Paulo, SP: Labrador, 63-68.

Corá, M. A. J., \& Motta, R. G. (2019). Intersetorialidade e redes: A trajetória do intelectual Luciano Antonio Prates Junqueira. São Pau- 
Io, SP: Labrador.

Faria, J. H., \& Meneghetti, F. K. (2011). Burocracia como organização, poder e controle. RAE - Revista de Administração de Empresas, 51(5), 424-439. doi:10.1590/S003475902011000500002

Faro, E. S. C., Amorim, M. C. S., Trevisan, L., \& Junqueira, L. A. P. (2010). Âncoras de carreira e transformações no modelo de administração: Estudo de caso do Tribunal de Contas da União (TCU). Cadernos EBAPE. $B R, 8(4), 710-733$.

Foucault, M. (2008). Microfísica do poder. Rio de Janeiro, RJ: Edições Graal.

França, G. C. de, Filho. (2008). Definido gestão social. In J. T. Silva, Jr., R. T. Mâish, \& A. C. Cançado, Gestão social: Práticas em debate, teorias em construção. Fortaleza, CE: Imprensa Universitária, 27-37.

Granovetter, M. (1973). The strength of weak ties. American Journal of Sociology, 78(6), 1360-1380.

Inojosa, R. M., \& Junqueira, L. A. P. (2008). Práticas e saberes: Desafios e inovações em gestão social. Organização \& Sociedade, 15(45), 171-180.

Junqueira, L. A. P. (1998). Descentralização e intersetorialidade: A construção de um modelo de gestão municipal. RAP- Revista de Administração Pública, 32(2), 35-48.

Junqueira, L. A. P. (1999, Novembro). Descentralização, intersetorialidade e rede como estratégias de gestão da cidade. Revista FEA-PUC-SP, 1, 57-72.
Junqueira, L. A. P. (2000). Intersetorialidade, transetorialidade e redes sociais na saúde. RAP- Revista de Administração Pública, 34(6), 35-45.

Junqueira, L. A. P. (2002). Trabalho voluntário e gestão das políticas sociais. In C. Perez, \& L. A. P. Junqueira (Orgs.), Voluntariado e gestão das políticas sociais (Vol. 1, pp. 136147). São Paulo, SP: Editora Futura.

Junqueira, L. A. P. (2004). Gestão Intersetorial das políticas sociais e o terceiro setor. Revista Saúde e Sociedade, 13(1), 25-26. doi: 10.1590/S0104-12902004000100004

Junqueira, L. A. P. (2006). Organizações sem fins lucrativos e redes sociais na gestão das políticas sociais. In M. Cavalcanti (Org.), Gestão social, estratégias e parcerias: Redescobrindo a essência da administração para o terceiro setor (Vol. 1, pp. 195-218). São Paulo, SP: Saraiva.

Junqueira, L. A. P. (2006, Novembro/Dezembro). Porto e meio ambiente. RAP- Revista de Administração Pública, 40(6), 971-973. Recuperado de http://www.scielo.br/ pdf/rap/ v40n6/02.pdf

Junqueira, L. A. P. (2008). Gestão social: Organização, parceria e redes sociais. In: A. C. Cançado, J. T. Silva, Jr., P. C. Schommer, \& A. S. Rigo (Orgs.), Os desafios da formação em gestão social. Palmas, TO: Provisão, 87103.

Junqueira, L. A. P., \& Misoczky, M. C. (2009). Redes sociais: Apresentação. RAP- Revista de Administração Pública, 43(5), 1003-1005. 
Junqueira, L. A. P., Maior, J. S., \& Pinheiro, F. P. (2011). Sustentabilidade: A produção científica brasileira entre os anos de 2000 e 2009. Revista de Gestão Social e Ambiental - RGSA, 5(3), 36-52.

Mendonça, P. M., Gonçalves-Dias, S. L. F., \& Junqueira, L. A. P. (2012, Setembro/Outubro). Gestão social: Notícias sobre o campo de estudos e práticas a partir das interações e debates do VI Enapegs. RAP- Revista de Administração Pública, 46(5), 1391-1408

Pinto, A. M. G., \& Junqueira, L. A. P. (2009). Relações de poder em uma rede do terceiro setor: Um estudo de caso. RAP-Revista de Administração Pública, 43(5), 1091-1116.

Said, E. W. (2005). Representações do intelectual: As Conferências Reith de 1993. São Paulo, SP: Companhia das Letras.

Sousa, M. R., Junqueira, L. A. P., \& Casas, A. L. Las. (2014). O perfil do franqueado divulgado pelos franqueadores na fase de prospecção de candidatos. Revista Organizações em Contexto-online, 10(19), 213243.

Sposati, A. (2019). Relações de poder em rede. In M. A. J. Corá, \& R. G. Motta, Intersetorialidade e redes: A trajetória do intelectual Luciano Antonio Prates Junqueira. São Paulo, SP: Labrador, 143-149.

\section{Notas}

1- Entrevista realizada com a pesquisadora e professora Rosinha Carrion, da Universidade Federal do Rio Grande do Sul (UFRGS), em março de 2018.

2- Entrevista realizada com a pesquisadora e professora Rosana de Freitas Boullosa, da Universidade de Brasília (UnB) e da Universidade Federal da Bahia (UFBA), em março de 2018.

3- Entrevista realizada com o pesquisador e professor Edgilson Tavares Araújo da Universidade Federal do Recôncavo Baiano (UFRB), em março de 2018.

4- Entrevista realizada com o pesquisador e professor Edson Sadao Ilzuka, do Centro Universitário da Fundação Educacional Inaciana "Padre Sabóia de Medeiros" (FEI), em março de 2018. 5- Prêmio Fenead foi uma iniciativa de estudantes da Federação Nacional de Estudantes de Administração que premiava iniciativas de terceiro setor dos estudantes de graduação em administração.

6- Entrevista realizada com a pesquisadora e professora Paula Schommer do Centro de Ciências da Administração e Socioeconômicas da Universidade do Estado de Santa Catarina (ESAG-UDESC), em março de 2018.

7- O primeiro Enapegs foi realizado em 2008 , em Juazeiro do Norte, pela Universidade Federal do Cariri. 